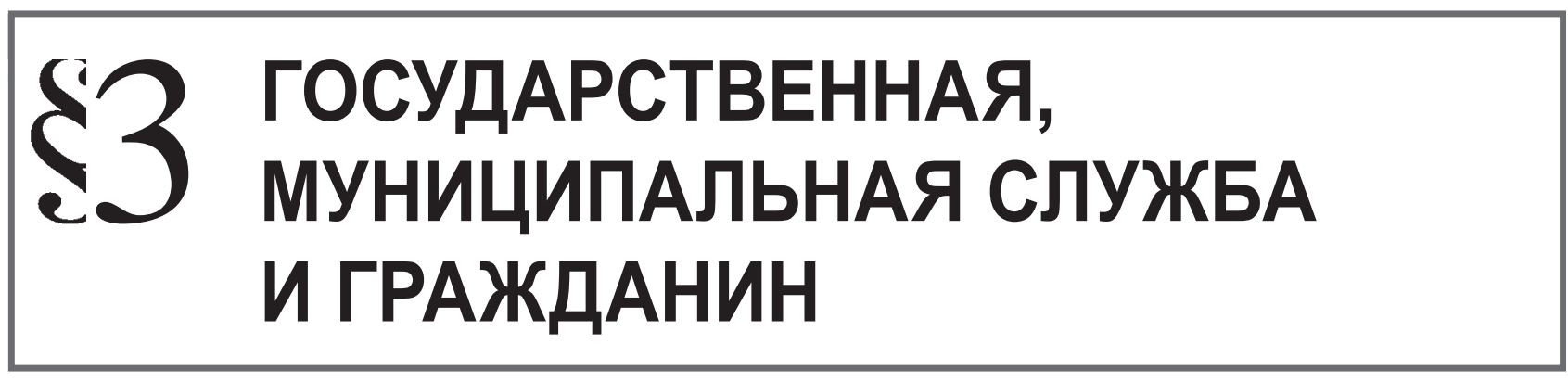

\title{
АДМИНИСТРАТИВНО-ПРАВОВЫЕ НАПРАВЛЕНИЯ ПОВЫШЕНИЯ ПРОФЕССИОНАЛЬНОЙ ДЕЯТЕЛЬНОСТИ ГОСУДАРСТВЕННЫХ СЛУЖАЩИХ
}

$\mathrm{C}$ ущностные черты административно-правовой эффективности модернизации государственной службы, изменения в статусе ее субъектов требуют обеспечения единства прав и обязанностей служащих, учета специфических особенностей и целостности системы оценки их профессиональной деятельности. Модернизация в сфере публичной службы - путь укрепления, прежде всего, административно-правовых и информационных начал инноватизации, ее комплексной оценки.

Информационное общество и формирующееся инновационное государство определяют сущность, содержание, направления совершенствования служебной деятельности и соответствующих правоотношений.

К таким направлениям, определенным разделом VII «Эффективная наука» Стратегии инновационного развития России относятся:

- улучшение качества кадрового потенциала;

- повышение эффективности сектора исследований и разработок, относящихся к кадровой политике, в том числе за счет реструктуризации ряда научных и управленческих центров;

- наращивание исследовательского потенциала на ключевых направлениях модернизации профессиональной деятельности управленческих кадров;

- развитие механизмов и инструментов координации и взаимодействия всех участников инновационного процесса административно-правового обеспечения эффективности служебной деятельности.

Существенное расширение спектра используемых инструментов и механизмов развития административ- но-правовой науки требует значительно более четкой координации предпринимаемых на этих направлениях усилий. Исходя из этого, целесообразно обеспечить развитие конкурентоспособных управленческих центров и кадровых служб, где будет концентрироваться значительная часть компетенций в сфере прикладных исследований и разработок. В том числе за счет максимальной интеграции науки административного права и учебных управленческих центров, обработки различных моделей их взаимодействия. Все это происходит в рамках расширения грантовой формы финансирования исследований с одновременным поэтапным сокращением доли финансирования в форме государственных контрактов на проведение научно-исследовательских работ в сфере подготовки и переподготовки управленческих кадров.

Предстоит уточнить и конкретизировать методики оценки уровня и качества научных проектов и организаций различного профиля с учетом специфики прикладных исследований, вузовской науки, отдельных областей исследований на основе современных международных методик и международного признания системных преобразований в деятельности российских служб и служащих. Для науки административного права актуальной является востребованность результатов проводимых исследований, в том числе российскими и зарубежными административистами и органами власти различного уровня ${ }^{1}$.

Процесс модернизации совершенствования службы, включая оптимизацию ее состава и деятельности, сопровождается созданием условий для возникно-

См.: Куракин А.В., Костенников М.В. Актуальные проблемы административного права. - М., 2013. 
вения новых правовых отношений на базе наиболее эффективных средств инновационного развития. С этой целью следует разработать систему выделения средств на создание учреждений, организаций, которые будут предусматривать финансирование и материально-техническое обеспечение новых организаций, управленческих структур, инноватизации деятельности их служащих.

Развитие сети национальных исследовательских центров должно стать ядром нового интегрированного научно-образовательного комплекса, обеспечивающего подготовку кадров нового, стратегического направления.

Таким образом, субъективную обязанность государственного служащего, в стратегической сфере, можно определить как предписываемую ему меру должного поведения в целях достижения показателей, намеченных Стратегией инновационного развития.

Под показателями реализации права служащего имеются в виду установленные Конституцией РФ, федеральным законом, иными правовыми актами и охраняемые государством возможности и способы профессиональной деятельности служащего по обеспечению должного функционирования государственных органов.

Помимо анализа показателей реализации прав служащих, основы правового статуса включают анализ выполнений служебных обязанностей. Как отмечают ученые-административисты, исполнение должностных обязанностей составляет основное содержание профессиональной деятельности служащего. Эти должные обязанности связаны с обеспечением исполнения полномочий органов управления и характеризуют сущность его служебной деятельности, ибо государство (государственный орган) принимает на работу гражданина, главным образом, с целью возложения на него соответствующих должностных обязанностей. Обязанность, как и право, воплощает в себе связь обладателя субъективного права с государством и с другим участником правоотношения управомоченным субъектом. Обязанность по своему содержанию прямо противоположна субъективному праву. Субъективное право - мера дозволенного государством поведения, а обязанность - мера должного поведения субъекта.

В юридической науке под обязанностью понимают меру должного поведения субъекта права, обусловленную правами другого лица, предъявляющего законные требования в целях удовлетворения своих интересов. Государственный служащий должен действовать строго в пределах своих полномочий, кото- рые закрепляются в должностной инструкции, в трудовом договоре, в регламенте.

Эффективность профессиональной деятельности зависит от того, насколько четко различаются должностные обязанности служащего в зависимости от органа, в котором осуществляется его деятельность, и от замещаемой должности

Эффективность осуществления обязанностей нанимателя в служебном правоотношении полностью корреллирует эффективности прав служащего. К таковым относятся обязанность обеспечивать ему надлежащие информационно-правовые, организационно-технические условия; своевременно и в полном размере выплачивать денежное содержание; предоставлять в установленном порядке время отдыха и т.п. ${ }^{2}$ Эффективность единства прав и обязанностей субъектов инновационно-служебных правоотношений обусловлено их тесной взаимосвязью. Речь в данном случае идет не только о том, что правам одного из участников служебного правоотношения корреспондируют обязанности другого. Вопрос заключается в том, что публично-правовая природа служебной деятельности во многих случаях требует сочетания прав и обязанностей в рамках общего понятия - инновационного полномочия.

Так, если рассматривать базовое право государственного служащего - право на осуществление своей профессиональной деятельности, то оно неразрывно связано с обязанностью осуществлять эту деятельность с учетом модернизации. Что же касается прав, реализуемых в инновационно-служебных правоотношениях, то они всегда связаны с обязанностью их творческой реализации. Так, право на профессиональную информацию о внедрении служащим инноваций связано с обязанностью другой стороны (нанимателя) информацию предоставлять. Напротив, право на должностной рост на конкурсной основе является именно правом и реализуется служащим в добровольном порядке путем участия в конкурсе на вакантную должность. Разумеется, проведя всю жизнь на государственной службе, служащий может это право ни разу не реализовать, что, конечно, не лучший вариант для эффективности работы самого служащего.

Таким образом, показателями эффективности профессиональной деятельности государственных служащих выступают:

1) масштабы публичности;

2) направленность на реализацию инновационных функций государства;

2 См.: Алехин А.П., Кармолицкий А.А. Административное право России. Основные понятия и институты. - М., 2004. C. 171. 
3) развитие внешневластного, административноправового характера служебной деятельности;

4) комплексность организационного структурирования, показателей совершенствования служебной деятельности в контексте Стратегии инновационного развития;

5) наличие прямой административно-правовой связи между эффективностью государственного управления, местного самоуправления, их органов и эффективностью деятельности служащих в соответствии с инновационным развитием России.

Серьезным недостатком исследования процесса модернизации административно-правового регулирования служебной деятельности является отсутствие новых стратегических связей между государственной службой и муниципальной службой. Это изолирует последнюю от влияния государственной службы, использования эффективного опыта действия единых принципов их организации и деятельности. Все это является препятствием для ротации кадров, для служебной карьеры муниципальных служащих и для развития инновационной деятельности управленческих кадров в целом.

Конечно, единство и целостность государственной службы и муниципальной службы могут находить воплощение не только в принципах их организации и функционирования, но и в институциональном взаимодействии и структурном оформлении системы показателей эффективности правового статуса государственных и муниципальных служащих. Ряд авторов приводят доводы в пользу объединения этих институтов. Так, В.В. Еремян указывает на властный характер государственной и муниципальной службыз ${ }^{3}$. Общим сущностным признаком, объединяющим правовое положение государственных и муниципальных служащих, является форма публичной власти, обеспечивающая единство властных полномочий соответствующих органов публичной власти.

Необходимость формирования единых правовых подходов и показателей эффективности регулирования государственно-служебных и муниципальнослужебных отношений заслуживает, с нашей точки зрения, поддержки и одобрения. Таким образом, существуют реальные предпосылки для того, чтобы служебно-правовая аналитика и служебно-правовая инноватика регулировали не только государственнослужебную, но и муниципально-служебную деятельность.

3 См.: Еремян В.В. Взаимосвязь государственной гражданской и службы как двух видов публичной службы и профессиональной деятельности (к постановке проблемы) // Право и политика. - 2006. - № 5. - С. 63.
Не следует исключать инновационно-правовой характер этой взаимосвязи. Прежде всего, государственная гражданская служба и муниципальная служба имеют наибольшее количество общих информационных черт стратегического направления. Специальные же виды государственной службы имеют ряд инновационных информационно-правовых особенностей (например, военной службы), которые менее применимы к муниципальной службе.

Ряд направлений и вопросов (принципы государственной и службы, право равного доступа на государственную и муниципальную службу, исчисление стажа государственной и службы, формы денежного содержания государственных и муниципальных служащих и некоторые другие) могут иметь единое правовое регулирование не только для государственной службы, но и для всех видов публичной службы.

Однако приходится констатировать, что современное законодательство о государственной службе и муниципальной службе пошло по пути расхождения не только этих институтов, но и безучастного отношения к их инновационно-правовому характеру.

Видимо, в перспективе будет сформирована законодательная база, которая в целом урегулирует инновационно-правовую сферу публичной службы РФ, обусловленную становлением инновационного государства и информационного общества. В настоящее время в российской правовой науке мало используется принятый в общемировой правовой практике термин «информационная открытость публичной службы».

Вместе с тем назрела необходимость введения в российское право понятия, объединяющего все виды службы, направленные на достижение стратегических целей государственного и муниципального управления в информационном обществе. Необходимость такого нововведения отмечается в управленческой практике.

Для государственной службы, как и для службы муниципальной, характерно преобладание императивного режима административно-правового направления регулирования отношений: разрешено только то, что прямо указано в законе. Поэтому в рамках модернизации, в части развития правового обеспечения эффективности модернизации государственной службы, необходимо реализовать позитивный потенциал правового регулирования складывающихся в этих сферах отношений на основе их детальной регламентации нормами и институтами главным образом административного права, с помощью информационного и других сравнительно разных отраслей права. 
Формулируя единые подходы к настоящему правовому регулированию государственной службы, необходимо иметь в виду, что при несомненном сходстве (в особенности между государственной гражданской службой и муниципальной службой) эти виды служебной деятельности имеют и определенные отличия. Они проистекают не только из территориального масштаба, но и из самой сферы инновационной, правовой, властно-управленческой деятельности. В том числе, из функциональной специфики, особенностей компетенции, полномочий государственных и муниципальных органов.

Повышение эффективности государственной службы предопределено ее неразрывной связью не только с муниципальной службой, но и с такими институтами, как инновационное государство и информационное общество.

Включение государственного служащего в систему стратегического государственного управления позволяет строить новые административно-правовые отношения с ним на таких направлениях, как стабильность, информационность, характеризующиеся тем, что в течение всей служебной карьеры служащий может осуществлять свою деятельность в различных муниципально-структурных подразделениях и государственных органах, при этом будучи уверенным в сохранении своего административно-правового статуса и его инновационных черт в форме, например, служебно-административного кодекса.

Термин «служебно-административный кодекс» в настоящее время не используется в специальной юридической литературе. В рамках монографических и диссертационных исследований чаще всего употребляется термин «модель»4. Такое внимание к моделированию объясняется тем, что основная миссия юридической науки заключается в определении тех средств и методов правового регулирования, которые являются наиболее эффективными и позволяют наилучшим образом привести общественные отношения, возникающие в процессе служебной деятельности, к заранее определенному, запрограммированному состоянию информационного общества. Разработанные административно-правовой наукой средства и методы, предложенные ею конкретные правовые нормы воспринимаются в процессе правотворчества и переносятся в действующее законодательство.

Сущность же предлагаемого к разработке кодекса как правового и общенаучного явления состоит в отражении новых, прежде всего административно-

4 См.: Ткаченко С.В. Современная модель российского федерализма // Право и политика. - 2009. - № 10. - С. 203. правовых, информационно-правовых, стратегических явлений объективной действительности с целью их изучения и прогнозирования их развития.

В кодексе получат отражение практика модернизации как полное представление об изменении реально существующих правовых явлений в профессиональной деятельности управленческих кадров в контексте Стратегии инновационного развития. Служебно-административный кодекс, его инновационное содержание станет результатом развития, формой отражения и средством выражения внутренней структуры сложных правовых явлений, каким является служебно-правовая аналитика и служебно-правовая инноватика. Последние несут информацию об исследуемых объектах и выполняют специальную задачу обеспечения эффективности модернизации профессиональной деятельности управленческих кадров.

В целом, можно заметить, что у разных специалистов сложились различные (а нередко и диаметрально противоположные) взгляды на понимание эффективности регулирования служебно-правовых отношений. Так, в науке административного права больше всего исследуются правоотношения в сфере государственной службы, под которыми понимаются отношения государственно-управленческого характера, возникающие при организации и практическом осуществлении властной исполнительно-распорядительной деятельности органов государственного управления и имеющие направленность на реализацию управленческих функций государства, публичной власти ${ }^{5}$. Однако здесь ни слова не сказано о модернизационной, стратегической, инновационной, информационной сущности (составляющей) служебной деятельности.

Вместе с тем, комплексно рассматривая служебную деятельность, ее правоотношения, необходимо указать на связь, во-первых, эффективности этих отношений служащего с государственным органом, возникающих в связи с информационно-правовым источником - Конституцией, во-вторых, в связи с поступлением на государственную службу, ее прохождением и прекращением. В правовом аспекте их лучше именовать «внутриправовыми» отношениями. Одновременно они являются трудовыми отношениями и регулируются нормами трудового права. В-третьих, эффективность этого отношения государственного служащего с

\footnotetext{
См.: Гусев А.В. Российская государственная гражданская служба: проблемы правового регулирования. - Екатеринбург, 2005; Литвинцева Е.А. Анализ зарубежного опыта правового регулирования государственной гражданской службы. - М., 2008.
} 
третьими лицами - организациями или гражданами, зависит от эффективности отношений, возникающих в соответствии с компетенцией органа, в котором служащий состоит на службе.

В настоящее время вся система государственной службы по тем или иным причинам действительно характеризуется наличием системных показателей эффективности модернизационно-служебной деятельности.

Представляется необходимым в настоящее время выделить следующие показатели эффективности модернизационно-служебной деятельности:

- развитие модернизационно-служебной деятельности, будучи именно системой правоотношений, что указывает на ее модернизационно-правовую и административно-правовую природу и отличие от трудовых правоотношений;

- наличие одной из сторон модернизационно-служебной деятельности, информации из новой управленческой жизни: Российской Федерации, субъекта РФ или муниципального образования;

- связанность правовых отношений с осуществлением властной деятельности в модернизационной сфере. Государственные и муниципальные служащие либо непосредственно реализуют полномочия, либо обеспечивают их реализацию;

- возникновение инновационной служебной деятельности применительно к отдельным видам государственной службы (опубликование акта о назначении на должность; публично принятый контракт о прохождении службы в условиях модернизации; трудовой договор, ставший достоянием коллектива служащих. В перспективе, при формировании единого массива служебного законодательства, единственным основанием возникновения служебных правоотношений должен стать, на наш взгляд, публично изданный акт о приеме на государственную службу;

- гораздо большая мобильность инновационнослужебной деятельности, ее правоотношений, чем трудовых и иных отношений. В ряде схожих случаев, когда трудовые правоотношения прекращаются, служебная деятельность продолжает существовать;

- инновационность служебной деятельности, которая характеризуется также публичным включением государственного служащего в аппарат государственного управления. Поступая на службу в орган государственной власти или местного самоуправления, служащий встраивается в информационно-организованную систему подчинения не только непосредственному руководителю, но и другим вышестоящим органам и должностным лицам, работающим на основе доступности к инновациям и информационной открытости;

- определенность важнейших элементов такой служебной деятельности установлена законодательством в императивном порядке, которые не могут изменяться по усмотрению их сторон.

Итак, на основе сказанного выше эффективность инновационной служебной деятельности можно охарактеризовать как урегулированные нормами права и охраняемые принудительной силой государства результативные, инновационные общественные отношения, сторонами которых являются государственные служащие, с одной стороны, и соответствующие публичные образования (Российская Федерация, субъекты РФ), с другой. Эффективность всегда возникает в процессе плодотворной организации и функционирования всех видов профессиональной деятельности, связанной с осуществлением властных полномочий на главных административно-правовых направлениях.

\section{Библиографический список:}

1. Алехин А.П., Кармолицкий А.А. Административное право России. Основные понятия и институты. - М., 2004.

2. Гусев А.В. Российская государственная гражданская служба: проблемы правового регулирования. - Екатеринбург, 2005

3. Еремян В.В. Взаимосвязь государственной гражданской и службы как двух видов публичной службы и профессиональной деятельности (к постановке проблемы) // Право и политика. - 2006. - № 5.

4. Куракин А.В. Государственная служба и коррупция. - М., 2009.

5. Куракин А.В., Костенников М.В. Акутальные проблемы административного права. - М., 2013.

6. Кулешов Г.Н. Административно-правовое регулирование информационного обеспечения в системе государственной гражданской службы: дис. ... канд. юрид. наук. - М., 2010.

7. Лебедева Н.Н. Доступ граждан к информации о деятельности органов государственной власти // Вестник Московского университета. - Серия 11. Право. - 2005. - № 5. 


\section{Административное и муниципальное право 7 (67) 2013}

8. Литвинцева Е.А. Анализ зарубежного опыта правового регулирования государственной гражданской службы. - М., 2008.

\section{References (transliteration):}

1. Alehin A.P., Karmolickiy A.A. Administrativnoe pravo Rossii. Osnovnye ponyatiya i instituty. - M., 2004.

2. Gusev A.V. Rossiyskaya gosudarstvennaya grazhdanskaya sluzhba: problemy pravovogo regulirovaniya. - Ekaterinburg, 2005

3. Eremyan V.V. Vzaimosvyaz' gosudarstvennoy grazhdanskoy i sluzhby kak dvuh vidov publichnoy sluzhby i professional'noy deyatel'nosti (k postanovke problemy) // Pravo i politika. - 2006. — № 5.

4. Kurakin A.V. Gosudarstvennaya sluzhba i korrupciya. - M., 2009.

5. Kurakin A.V., Kostennikov M.V. Akutal'nye problemy administrativnogo prava. - M., 2013.

6. Kurakin A.V., Kostennikov M.V. Akutal'nye problemy administrativnogo prava. - M., 2013.

7. Kuleshov G.N. Administrativno-pravovoe regulirovanie informacionnogo obespecheniya v sisteme gosudarstvennoy grazhdanskoy sluzhby: dis. ... kand. yurid. nauk. - M., 2010.

8. Lebedeva N.N. Dostup grazhdan k informacii o deyatel'nosti organov gosudarstvennoy vlasti // Vestnik Moskovskogo universiteta. - Seriya 11. Pravo. - 2005. - № 5.

9. Litvinceva E.A. Analiz zarubezhnogo opyta pravovogo regulirovaniya gosudarstvennoy grazhdanskoy sluzhby. - M., 2008. 